\title{
EXPERIMENTAL COMPARATIVE STUDY OF DIFFERENT TREATMENT CHAMBERS FOR FOOD PROCESSING USING PULSED ELECTRIC FIELD
}

\author{
Yassine Bellebna $^{1,2, \bowtie}$, Said Nemmich ${ }^{1,2}$, Kamel Nassour ${ }^{1,2}$, Amar Tilmatine ${ }^{1,2}$ \\ ${ }^{1}$ APELEC Laboratory, Djillali Liabes University of Sidi Bel-Abbes, Algeria \\ ${ }^{2}$ Faculty of Electrical Engineering, Djillali Liabes University of Sidi Bel-Abbes, Algeria \\ \yassinebellebna@yahoo.fr \\ https://doi.org/10.34302/crpjfst/2020.12.5.5 \\ Article history: \\ Received: \\ 28 August 2020 \\ Accepted: \\ 25 December 2020 \\ Keywords: \\ Beet \\ Absorbance \\ Yield juice \\ Electroporation \\ Pulsed electrical field (PEF) \\ Electrodes

\section{ABSTRACT} \\ The major challenge today lies in the application of PEF in the industry; it \\ requires an ever-increasing processing rate by seeking ways to \\ continuously reduce energy consumption. All treatment chambers (TC) \\ currently used in industry and in research laboratories, the product to be \\ treated is placed in one volume unit delimited between two electrodes \\ energized by a pulsed voltage which the electric field lines which are \\ perpendicular to the electrodes are monoaxial and oriented almost in only \\ one direction. The objective of this paper is to study experimentaly a new \\ TC model comprising one, two or three monoaxial PEF units in parallel \\ (TC1, TC2, TC3) and another biaxial PEF units (TC4) consisting of \\ several "alternate ground-HV electrodes," in order to increase the \\ processing flow rate and save more energy. The treatment chambers made \\ of Plexiglas have a square paralelipedic shape, in which are placed either \\ two (TC1), three (TC2), five (TC3) vertical and parallel stainless steel \\ electrodes. One, Two or three of these electrodes are grounded and placed \\ on the side walls of the chamber, while the high voltage electrode is placed \\ in the central plane at equal distance between the ground electrodes. These \\ chambers have been compared to biaxial treatment chamber comprising \\ four identical metal plates placed on the side walls of a square shape \\ (TC4). The obtained results have shown that the proposed model TC3 and \\ TC4 are better than the two others in terms of extracted juice mass and \\ energy consumption.
}

\section{Introduction}

The food industry is continually increasing because of worldwide demand (Heinz et al. 2002; Rao and Lund. 1986). The mechanical expression is widely used in the processes of solid-liquid separation for extraction of fruit juices and vegetable oils, dewatering of fibrous materials, etc. On the other hand, cell membrane acts as a physical barrier in removing the intracellular substances (water, juices and solutes) from plant food tissues in solid-liquid extraction and drying. Thus, the permeabilization of the cell membrane in a plant food tissue causes the release of intracellular water and solutes (secondary metabolites) to migrate in an external medium (Aguilera and Stanley. 1999).

Presently, the rupture of the cell membrane can be obtained by means of several methods according to the desired degree of disintegration and to the particular application. It is possible to identify: thermal and nonthermal methods. High temperature is used in food preservation and in pre-treatment and complementary stages before extraction processes. In this way it is possible to achieve a high degree of cell membrane breakdown, but due to the thermal denaturation of the cell membrane induced by heating; this treatment 
damages sensory properties (Ponant et al. 1988; Jemai and Vorobiev. 2006).

Pulsed electric field (PEF) treatment is an innovative and promising method for nonthermal processing of foodstuff. It is a good alternative to conventional cell membrane permeabilization methods such as thermal treatments and the addition of chemicals as well as of enzymes (Rauh et al. 2009).

Pulsed electric field treatment is an unconventional method for liquid and food products which is efficient for juice yield intensification and for improving the product quality in juice production (Kinga et al. 2019; Roman et al. 2013), processing of vegetables and plant raw materials (McLellan et al. 1991; Bazhal and Vorobiev. 2000), food stuffs processing (Aashish and Divya. 2018), winemaking (Elif et al. 2014) and sugar production (Lebovka et al. 2007; Kalmykova. 1993).

In the last few years, several studies have demonstrated the ability of intense treatments to obtain safe and shelf-stable liquid foods. Further, novel applications such as improvement of mass transfer processes or generation of bioactive compounds by using moderate field strengths are under current development (Muhammed and Gulsun. 2017; Jeyamkondan et al.1999).

One of emerging and promising method is the combined PEF and pressure application, which demonstrates significant yield intensification for juice extracted from apples and beets and clarification of the extracted juice. But the major problem arising from simultaneous application of mechanical expression and PEF treatment is the choice of optimal modes of treatment.

The difficulty of the problem is that PEFtreated juice extraction process depends on multiple factors. The list of factors influencing the outcome of the process includes the interelectrodes interval, the high voltage level, the electric field, the pulse duration, the number of pulses, the average power, the pressure level and so on,(Qamar et al. 2017).

The aim of the present study is an experimental comparative study of the influence of treatment chamber efficiency in yield and quality beet.

\section{Materials and methods}

\subsection{Pulsed electric field for electroporation}

Exposing a biological cell (plant, animal and microbial) to a high intensity electric field $(\mathrm{kV} / \mathrm{cm})$ using very short pulses ( $\mu$ s to $\mathrm{ms}$ ) induces the formation of temporary or permanent pores on the cell membrane (figure 1). This phenomenon, called electroporation, causes the permeabilization of cell membrane i.e. an increase of its permeability and if the intensity of the treatment is sufficiently high, cell membrane disintegration occurs.

The electroporation for permeabilization of the cell membrane is used in many fields such as biotechnology, cell biology, medicine and food industry (figure 2). Mass transfer processes such as solid-liquid extraction and drying as well as food preservation are important unit operations of the food industry requiring the electroporation of the cell membrane.
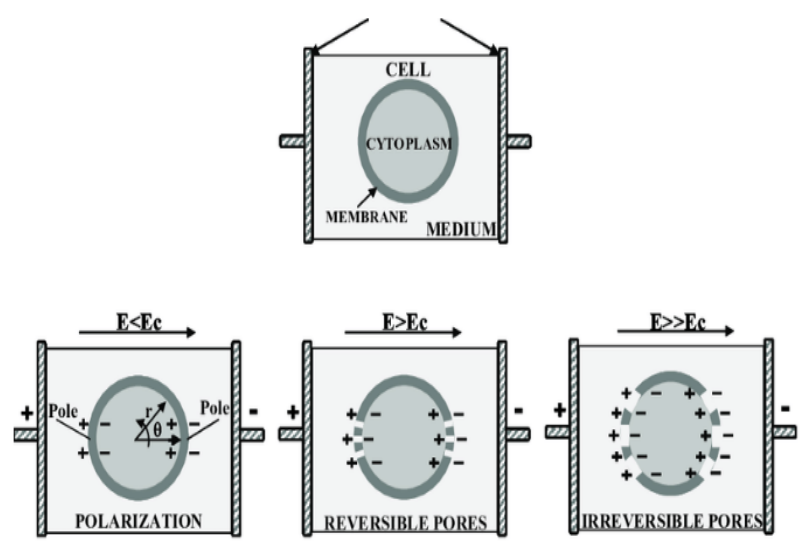

Figure.1. Schematic depiction of the permeabilization mechanism of a biological cell membrane exposed to an electric field $\mathrm{E}$. 


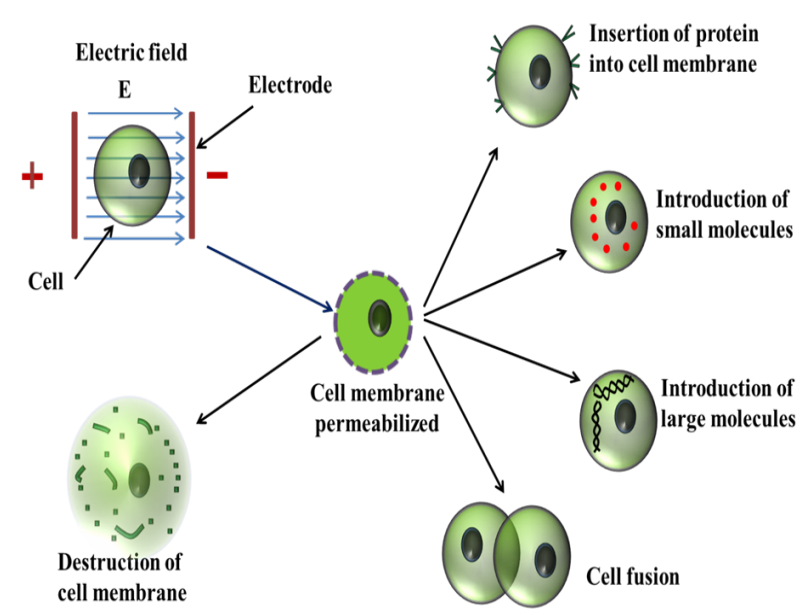

Figure.2. Electroporation applications of the cell membrane

\subsection{PEF processing system}

A PEF system for food processing in general consists of three basic components: a high voltage pulse generator, a treatment chamber and a control system for monitoring the process parameters (figure 3 ).

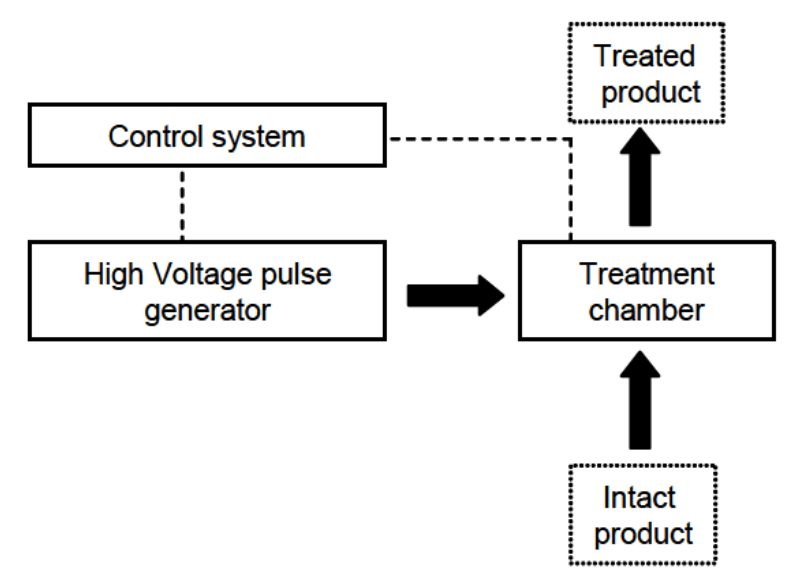

Figure 3. Descriptive representation of a pulsed electric field system for food processing.

\subsection{Materials}

Fresh beets, of average mass $60 \mathrm{~g}$ each one, were used. After sorting and cleaning operations, a homogenous mash was obtained using a domestic food processor. Before each experiment, the mash was properly mixed to obtain a homogenous mixture. A beet paw sample of mass $80 \mathrm{~g}$ was used for each experiment. After PEF treatment, an extraction step was achieved using an extraction chamber and a hydraulic pressing machine (Mega, 15 tons). The PEF treated extracted juice was then analyzed by measuring both its mass using an electronic balance of $0.1 \mathrm{mg}$ precision and the betanine amount using a spectrophotometer (Optizen 200 plus) for $\lambda=530 \mathrm{~nm}$.

All experiments were performed while maintaining following factors at constant values: pulse repetition frequency $\mathrm{f}=1 \mathrm{~Hz}$, extraction pressure $\mathrm{P}=50 \mathrm{~kg} / \mathrm{cm} 2$, total pressing duration $\mathrm{t}=300 \mathrm{~s}$ and the interelectrodes gap $\mathrm{d}=60 \mathrm{~mm}$.

The experimental setup used in the present work is composed of a number of components, comprising a high DC voltage source, an energy storage capacitor, a spark gap switch and a treatment chamber (Figure.4). A DC high voltage supply (Spellman $40 \mathrm{kV}, 9 \mathrm{~mA}$ ) charges the bank of capacitors until producing the spark gap's breakdown, causing an abrupt voltage (shock) applied to the load (treatment chamber where the sample is disposed). The storage element is composed of three sets of five series capacitors $(2 \mu \mathrm{f}, 2 \mathrm{kV})$, with the possibility to reach a maximum voltage of 10 $\mathrm{kV}$ and a total capacitance of $1.2 \mu \mathrm{F}$.

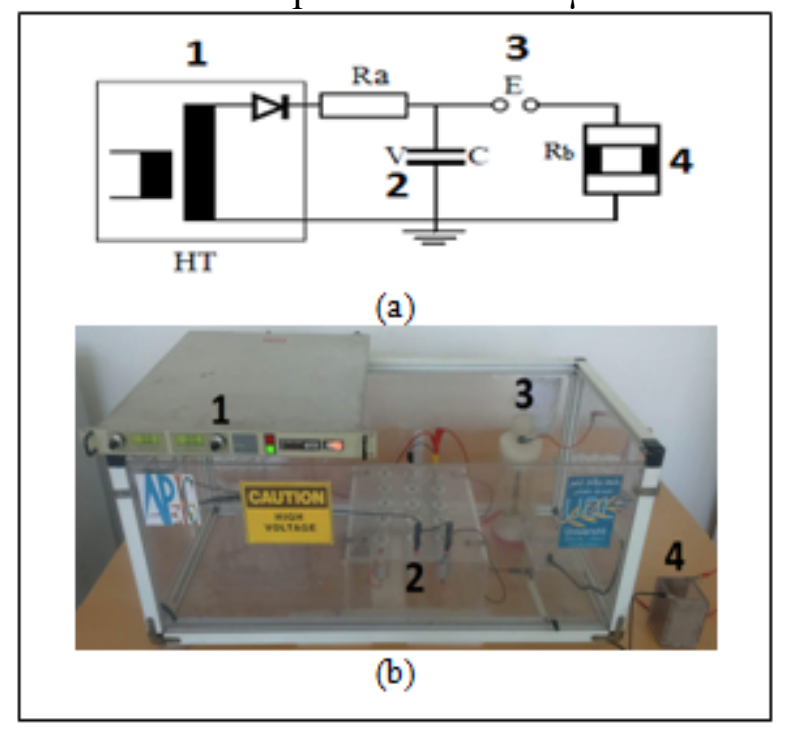

Figure.4. The pulse generator.

a) Descriptive schematic of the setup; b) The photography of the setup

1- HV DC power supply, 2-Set of capacitors, 3Spark gap switch, 4-Treatment chamber 
Four square paralelipedic treatment chambers made of Plexiglas, of dimensions $6 \times 6 \times 10 \mathrm{~cm}^{3}$, in which are placed vertical stainless steel electrodes, were used in this work. The model TC1 comprises two parallel and opposite electrodes of dimensions $6 \times 10$ $\mathrm{cm}^{2}$, the model TC2 is constituted of two units comprising three electrodes: one central HV electrode and two outside ground electrodes, the model TC3 is constituted of three units comprising five alternate $\mathrm{HV}$ and ground electrodes: two HV electrodes and three ground electrodes (Figure .5), while the model TC4 is constituted of four electrodes (Figure.6). For this latter, each pair of the adjacent metal plates form one electrode. The volume of both treatment chambers is $360 \mathrm{ml}$.

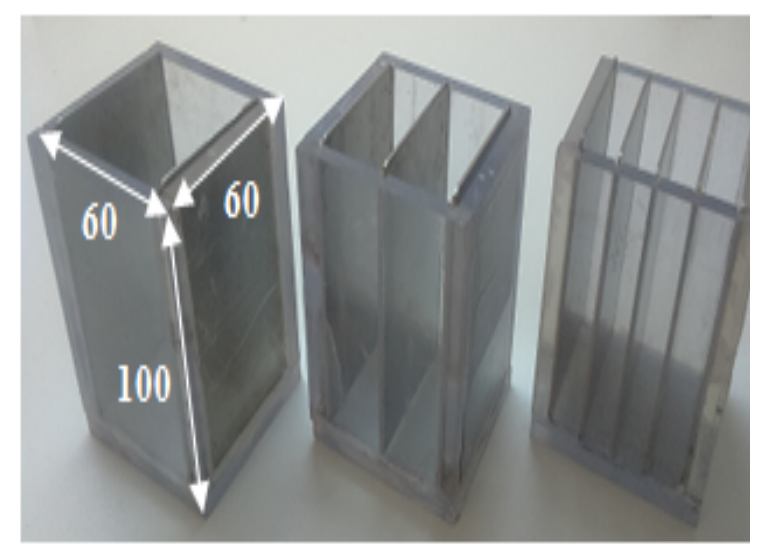

(TC1)
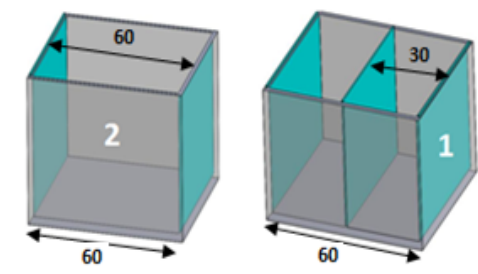

HV
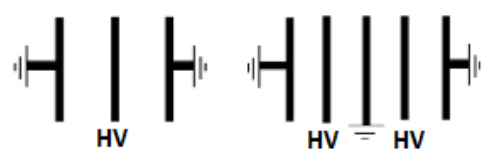

Figure.5. The treatment chambers (TC1, TC2 and TC3)

1: stainless steel electrodes; 2: paralelipedic treatment chambers (Dimensions in $\mathrm{mm}$ ).
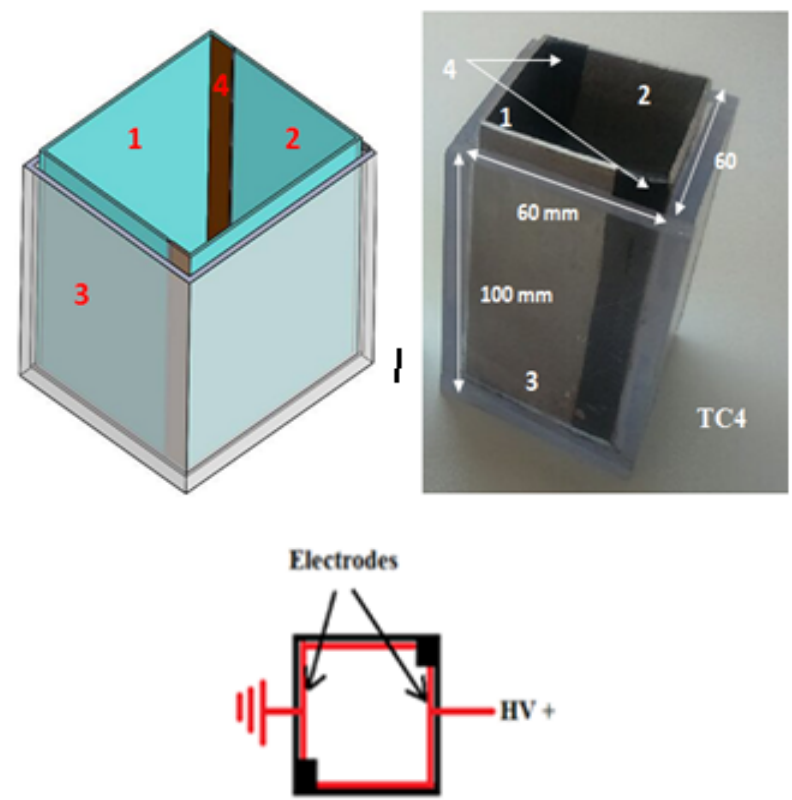

Figure.6. The treatment chambers TC4 1: Electrode HV. 2: Electrode ground.

3: Plexiglas. 4: Insulating.

\subsection{Methods}

An experimental investigation was performed to compare the PEF treatment efficiency between the three models. For each model, the influence of the applied voltage $(\mathrm{V}$, $\mathrm{kV}$ ), the pulses number (n) and the pulse duration $(T, \mu s)$ was analyzed. The pulse duration is determined by the corresponding value of the capacitance, as follows:

For $\mathrm{C}=0.2 \mu \mathrm{F}, \mathrm{T}=8 \mu \mathrm{s}$; for $\mathrm{C}=0.4 \mu \mathrm{F}, \mathrm{T}=20$ $\mu \mathrm{s}$, for $\mathrm{C}=0.8 \mu \mathrm{F}, \mathrm{T}=40 \mu \mathrm{s}$ and for $\mathrm{C}=1.2 \mu \mathrm{F}$, $\mathrm{T}=60 \mu$ s (Figure.7).

Moreover, the mass of extracted juice $m$ (g), the amount of Betatin expressed in terms of Absorbance Abs (\%) and the energy $\mathrm{W}=1 / 2 \mathrm{n}$ $\mathrm{CV}^{2}$ were considered significant to be considered as the response of the process. 

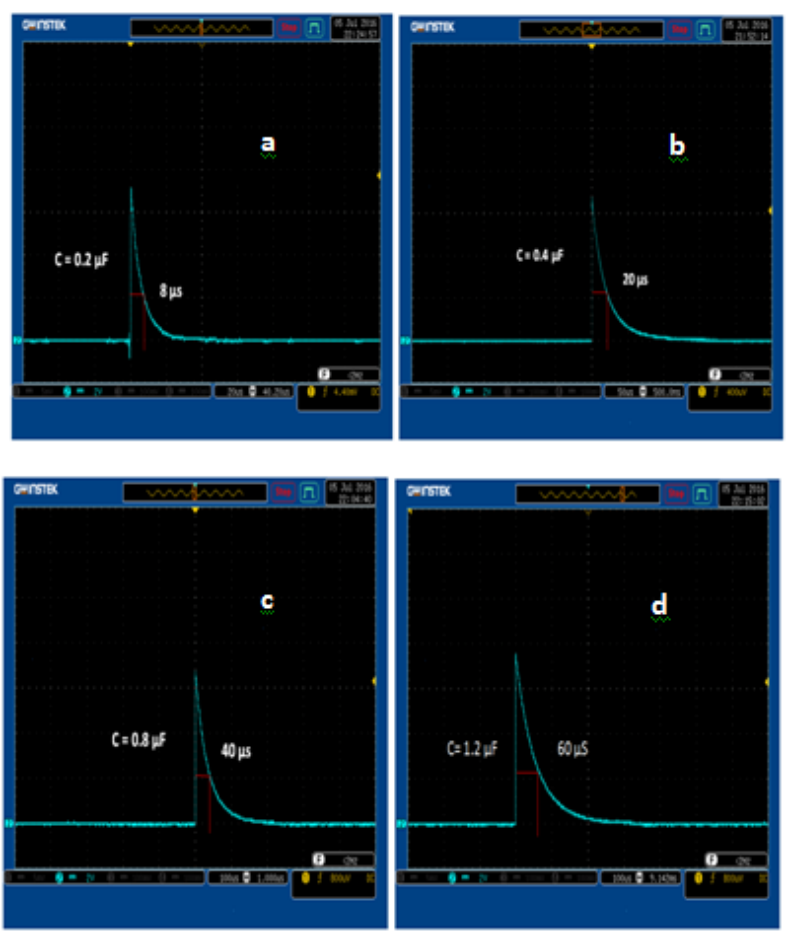

Figure.7. Current waveforms delivered by the pulse generator for different values of capacitance $\mathrm{C}$

a. $\mathrm{T}=8 \mu \mathrm{s}(\mathrm{C}=0.2 \mu \mathrm{F}), \mathrm{b} . \mathrm{T}=20 \mu \mathrm{s}(\mathrm{C}=0.4$ $\mu \mathrm{F})$, c. $\mathrm{T}=40 \mu \mathrm{s}(\mathrm{C}=0.8 \mu \mathrm{F}), \mathrm{d} . \mathrm{T}=60 \mu \mathrm{s}(\mathrm{C}=$ $1.2 \mu \mathrm{F})$

\section{Results and discussions}

For all the experiments carried out in this section, for each TC model, one factor was varied while the two other factors were kept constant. Thus, figures 8-14 represent the variation of the PEF treatment efficiency, in terms of juice extracted mass $\mathrm{m}$, absorbance Abs and Energy W, according to the voltage V, the pulses number $\mathrm{n}$ and the pulse width $\mathrm{T}$, respectively.

The obtained results of the experiments are plotted in Figures.8-13, representing the variation of the extracted juice mass $(\mathrm{m})$ and the absorbance (Abs) as function of the voltage $\mathrm{V}$, the pulses number $\mathrm{n}$ and the pulse duration $\mathrm{T}$ respectively for the four models of treatment chambers.

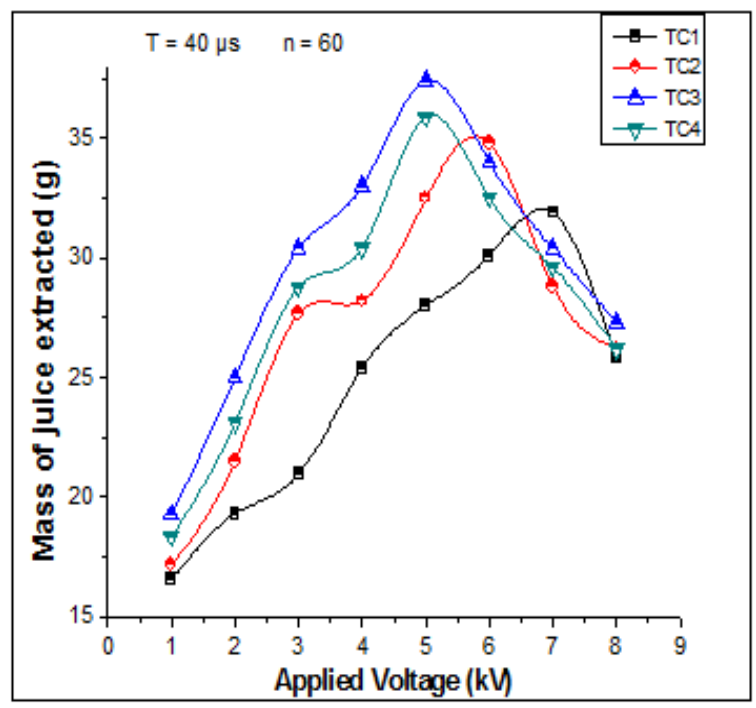

Figure.8. Mass of juice extracted according of the applied voltage for different TC model $(\mathrm{n}=60, \mathrm{~T}=40 \mu \mathrm{s})$

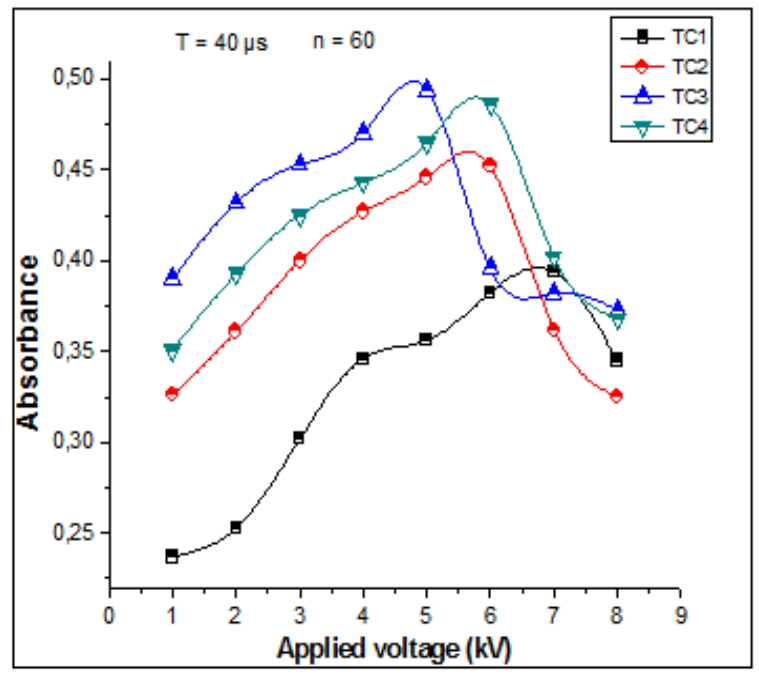

Figure.9. Absorbance of juice extracted according of the applied voltage for different TC model $(n=60, T=40 \mu s)$

As expected, the mass of extracted juice and the quantity of Betanine obtained with a PEF treated sample increases according to the applied voltage (Fig.8 - Fig.9), for the four chambers. Beyond a determined value of the voltage, the effect of the PEF treatment is inversed due to "oxidation" of the product. However, the treatment is more efficient for models TC2, TC3 and TC4 compared with the 
classic chamber $\mathrm{TC} 1$ comprising two electrodes. While for the model $\mathrm{TC} 1$, the optimal treatment was obtained for $\mathrm{V}=7 \mathrm{kV}$ $(\mathrm{m}=31.9 \mathrm{~g} \& \mathrm{Abs}=0.394)$, for others chambers greater values of $(\mathrm{m})$ and $(\mathrm{Abs})$ were obtained with smaller voltage.

However, comparing models TC2, TC3 and TC4 we see that the TC3 model gives better results in juice yield and betanine concentration due to significant value of energy provides for food processing at low voltages as a result of the better configuration of this chamber which promotes a high electric field.

Thus, for models TC3 and TC4, the optimal treatment was obtained for $\mathrm{V}=5 \mathrm{kV}(\mathrm{m}=37.4$ $\mathrm{g} \& \mathrm{Abs}=0.494)$, and $\mathrm{V}=5 \mathrm{kV}(\mathrm{m}=35.9 \mathrm{~g} \&$ $\mathrm{Abs}=0.465)$ respectively.

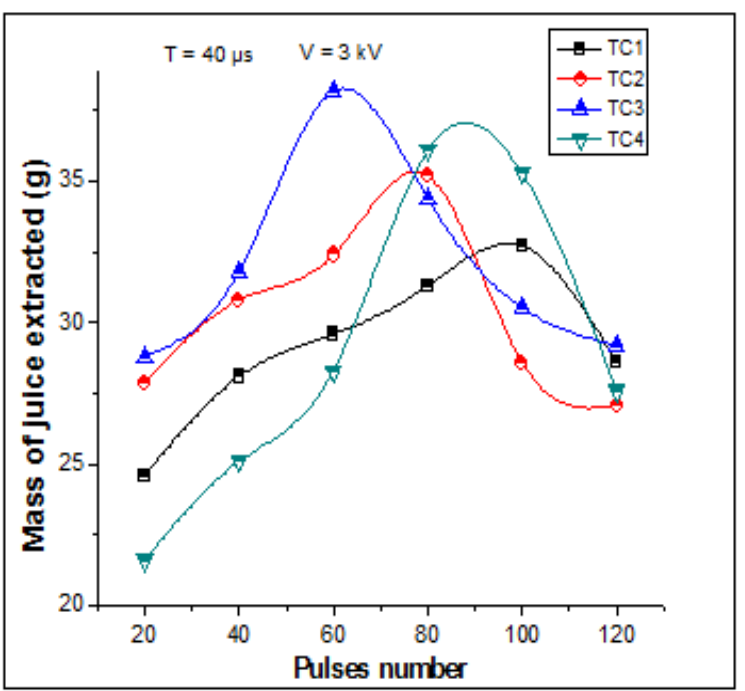

Figure.10. Mass of juice extracted according of the pulses number for different TC model $(\mathrm{V}=3 \mathrm{kV}, \mathrm{T}=40 \mu \mathrm{s})$

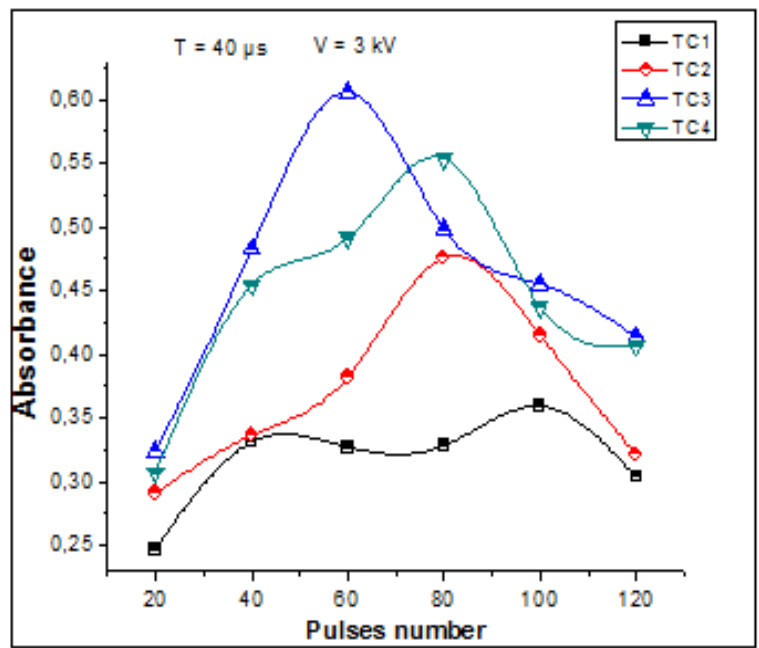

Figure.11. Absorbance of juice extracted according of the pulses number for different $\mathrm{TC}$ model $(\mathrm{V}=3 \mathrm{kV}, \mathrm{T}=40 \mu \mathrm{s})$

As seen in figures 10 and 11, the mass of extracted juice and the quantity of Betanine obtained with a PEF treated sample increases with pulses number, for the four chambers. The treatment is more efficient for models TC2, TC3 and TC4 compared with the classic chamber TC1. While for the model TC3, the optimal treatment was obtained for $\mathrm{n}=60$ pulses $(\mathrm{m}=38.2 \mathrm{~g} \& \mathrm{Abs}=0.606)$, for the other treatment chambers TC greater values of $\mathrm{m}$ and Abs were obtained with more pulses.

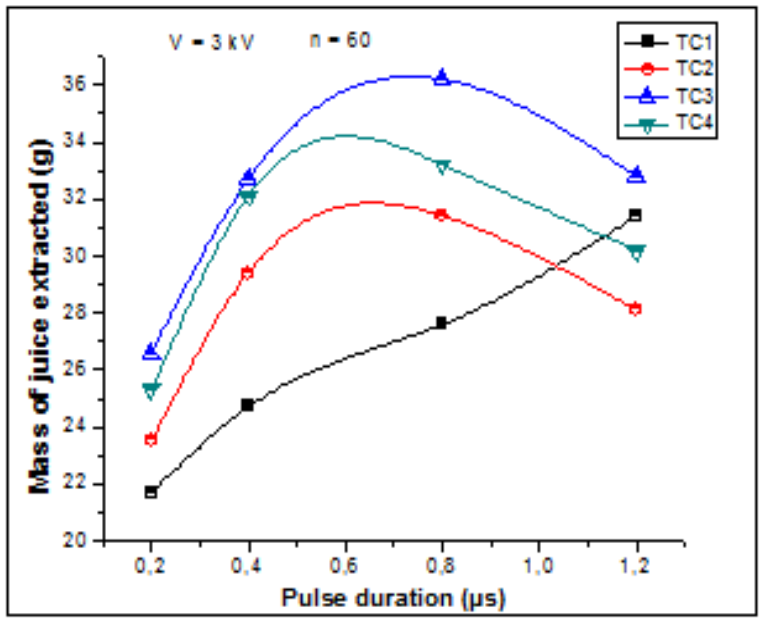

Figure.12. Mass of juice extracted according of the pulse duration for different TC $\operatorname{model}(\mathrm{V}=3 \mathrm{kV}, \mathrm{n}=60)$ 


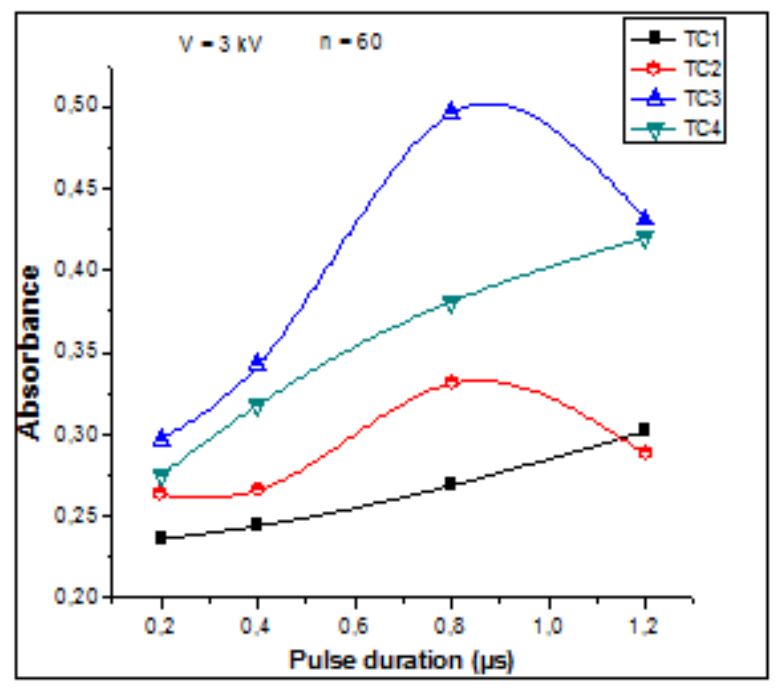

Figure.13 . Absorbance of juice extracted according of the pulse duration for different $\mathrm{TC}$ model $(\mathrm{V}=3 \mathrm{kV}, \mathrm{n}=60)$

On the other hand, the mass $(\mathrm{m})$ and absorbance (Abs) obtained with a PEF treated sample increases with the pulse width, for the four chambers (Figure 12 and 13), and decreases beyond a determined value. As for the previous factors, the treatment is more efficient for TC2, TC3 and TC4 models compared with the classic chamber. While for the model TC1, the optimal treatment was obtained for $\mathrm{T}=60 \mu \mathrm{s}(\mathrm{m}=31.4 \mathrm{~g} \& \mathrm{Abs}=$ 0.302), for the models TC2, TC3 and TC4 greater values were obtained with smaller pulse width. The optimal treatment was obtained for $\mathrm{T}=40 \mu \mathrm{s} \quad(\mathrm{m}=31.8 \mathrm{~g} \& \mathrm{Abs}=0.331)$ using model $\mathrm{TC} 2$, for $\mathrm{T}=40 \mu \mathrm{s}(\mathrm{m}=36.2 \mathrm{~g} \& \mathrm{Abs}=$ $0.496)$ using model TC3 and for $\mathrm{T}=40 \mu \mathrm{s}(\mathrm{m}=$ $33.2 \mathrm{~g} \& \mathrm{Abs}=0.381$ ) using model TC4. Indeed, the TC4 model represents a more efficiency treatment in comparison with the other models.

\subsection{Energy saving during the PEF treatment}

The following step is the comparing of the energy consumption and saving energy for four TC1, TC2, TC3 and TC4 chambers (Table 1 and figures $14 \& 15$ ).
Table 1. Energy consumption during the PEF treatment

\begin{tabular}{|c|c|c|c|c|c|}
\hline \multicolumn{2}{|l|}{ TC1 } & \multicolumn{3}{c|}{ TC2 } \\
\hline Mass(g) & Abs & W(J) & Mass(g) & Abs & W(J) \\
\hline 31.9 & 0.394 & 980 & 34.2 & 0.452 & 720 \\
\hline \multicolumn{3}{|c|}{ TC3 } & \multicolumn{3}{c|}{ TC4 } \\
\hline Mass(g) & Abs & W(J) & Mass(g) & Abs & W(J) \\
\hline 37.4 & 0.494 & 500 & 35.9 & 0.486 & 500 \\
\hline
\end{tabular}

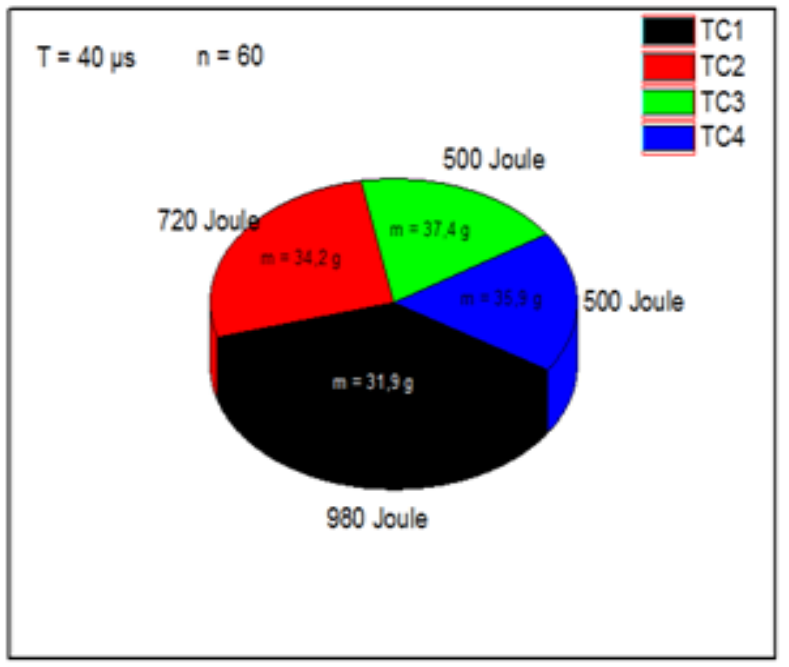

Figure.14. Energy consumption of optimal values for four TC models

$$
(\mathrm{T}=40 \mu \mathrm{s}, \mathrm{n}=60)
$$

Saving energy for treatment chambers TC2, TC3 and TC4 compared to the TC1 treatment chamber can be calculated by the following equation:

$$
W_{\text {saving }}=\frac{W_{T C 1}-W_{T C i}}{W_{T C 1}}
$$

TCi : Energy of TC2, TC3 or TC4 respectively.

An energy saving of $17.3 \%, 49 \%$ and $49 \%$ were achieved for models TC2, TC3 and TC4 respectively (Figure.15).

The advantage of the multi-units chambers (models TC2 and TC3) is that for the same voltage the electric field is increased compared to the "one-unit" chamber comprising two electrodes. For example, when a voltage of 6 $\mathrm{kV}$ is applied, the electric field of the models TC1, TC2 and TC3 is equal to 1,2 and 4 $\mathrm{kV} / \mathrm{cm}$ respectively. 
In other hand, for the model TC4 the electric field in this case is distributed at all surface of the food during treatment winch gives better treatment and results. However, this model of treatment chamber presents possibility of breakdown between electrodes that affected on the treatment process and subsequently the juice yield and the Betanine concentration compared with treatment chamber TC3 model.

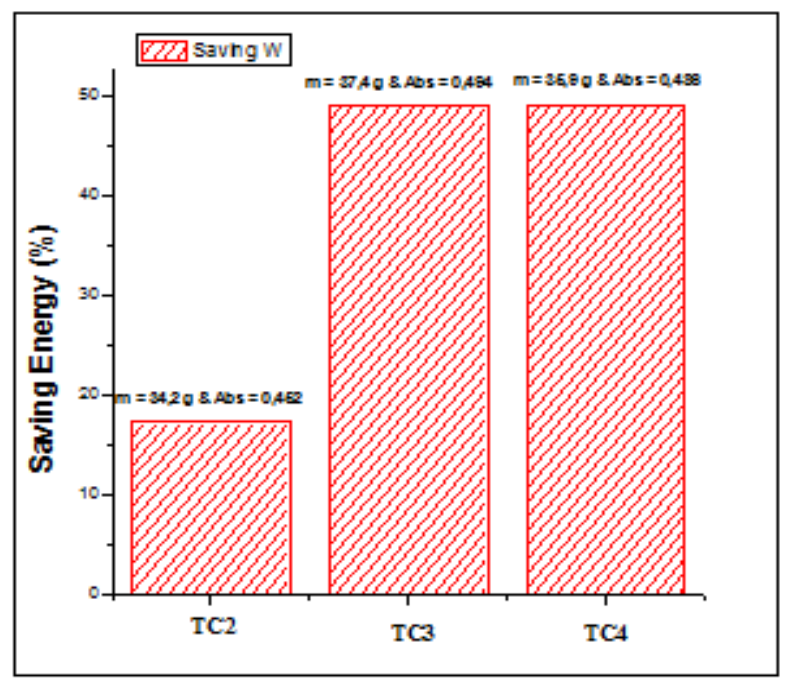

Figure.15. Saving energy consumption of optimal values for different TC model

$$
(\mathrm{T}=40 \mu \mathrm{s}, \mathrm{n}=60)
$$

\section{Conclusions}

The present paper describes an experimental comparative analysis between four square treatment chambers of same dimensions but having either two three four or five metal electrodes placed on the side walls which is named TC1, TC2, TC4 and TC3 respectively. For TC4 which is constituted four electrodes, each pair of the adjacent metal plates form one electrode. The experimental analysis was made by measuring the mass of PEF pretreated extracted juice from beet and the amount of Betanine using a spectrophotometer. The obtained results, have shown that the model with four electrodes TC4 and the model with five electrodes TC3 are more efficient compared with TC1 and TC2 model, because higher quantities of juice and Betanine were obtained. On other hand, TC3 model which is constituted multi-units treatment chamber remains the best configuration because of its simplicity of realization and utilization to industrial level, so that there will be possible to increase the voltage and electric field treatment without a risk of breakdown between the electrodes.

\section{References}

Aashish, C. I, Divya, M. S. (2018). A Study on the Food Processing Industry and Its Quality Conscious Effect. International Journal of Mechanical and Production Engineering Research and Development. 8(2), 1161-1170.

Aguilera, J.M., \& Stanley, D.W. Microstructural principles of food processing and engineering. 1999. Second Edition 432 pages.

Bazhal, M.I., \& Vorobiev, E.I. (2000). Electric treatment of apple slices for intensifying juice pressing. Journal of the Science of Food and Agriculture. 80 (11), 1668-1674.

Elif E. Abca Gulsun Akdemir Evrendilek. (2014). Processing of Red Wine by Pulsed Electric Fields with Respect to Quality Parameters. Journal of Food Processing and Preservation. 39 (2), 758-767.

Heinz, V., Alvarez, I., Angersbach, A., Knorr, D. (2002). Preservation of liquid foods by high intensity pulsed electric field- basic concept for process design. Trends in Food Science and Technology, 12(3-4), 103111.

Muhammed Yilmaz and Gulsun Akdemir Evrendilek. (2017). Impact of the Pulsed Electric Field Treatment on Bioactive Food Compounds: Bioaccessibility and Bioavailability. Journal of Nutrition \& Food Sciences. 7(3), 2-6.

Jemai, A.B; Vorobiev, E. (2006). Pulsed Electric Field Assisted Pressing of Sugar Beet Slices: towards a Novel Process of Cold Juice Extraction. Biosystems Engineering. 93 (1), 57-68

Jeyamkondan, S., Jayas, D.S. et Holley, R.A. (1999). Pulsed electric field processing of foods. Journal of Food Protection, 62(3),1088-1096. 
Kalmykova, I.S. (1993). Application of electroplasmolysis for intensification of phenols extracting from the grapes in the technologies of red table wines and natural juice. PhD Thesis, Odessa Technological Institute of Food Industry, Odessa, Ukraine.

Kinga, D., Aneta, K., Tomasz, D., Paweł K., Marek O., Karol B. \& Maciej O.(2019). Effect of pulsed electric field treatment on shelf life and nutritional value of apple juice. Journal of Food Science and Technology. 56(1), 1184-1191.

Lebovka. N.I., Shynkaryk. M.V., El-Belghiti. K, Benjelloun. H., Vorobiev. E. (2007) Plasmolysis of sugarbeet: Pulsed electric fields and thermal treatment. Journal of Food Engineering. 80 (4), 639-644.

McLellan, M.R., Kime, R.L., \& Lind, L.R. (1991). Electroplasmolysis and other treatments to improve apple juice yield. Journal of Science Food Agriculture. (57), 303-306.

Ponant, J., Foissac, S. \& Esnault, A. (1988). The alkaline extraction of sugar beet. Zucker Industrie.113(8), 665-676.

Qamar, Abbas Syed, Anum Ishaq, Ubaid Ur Rahman, Sadia Aslam, Rizwan Shukat. (2017). Pulsed electric field technology in food preservation: a review. Journal of Nutritional Health \& Food Engineering, 6(5):168-172.

Rauh, C., Baars, A. \& Delgado. A. (2009). Uniformity of enzyme inactivation in a short-time high-pressure process. Journal of Food Engineering. 9(1), 154-163.

Rao, M.A., \& Lund, D.B. (1986). Kinetics of thermal softening of food. a review. Journal of Food Processing and Preservation. 10(1),311-329.

Roman, B., Sieh, N., Stefan, T. (2013). Pulsed Electric Field Processing of Orange Juice: A Review on Microbial, Enzymatic, Nutritional, and Sensory Quality and Stability. Comprehensive Reviews in Food Science and Food Safety. 12(5):455 - 467.

\section{Acknowledgments}

The authors gratefully acknowledge the financial support by Algerian Ministry of Higher Education and Djillali Liabes University of Sidi Bel abbes. 